\title{
Average Happiness and Dominant Family Type in Regions in Western Europe around 2000
}

\author{
Gaël Brulé, Ruut Veenhoven \\ EHERO, Erasmus University of Rotterdam, Rotterdam, The Netherlands \\ Email: brule@ese.eur.nl
}

Received 10 October 2014; revised 8 November 2014; accepted 25 November 2014

Academic Editor: Angel Paniagua, Spanish Council for Scientific Research, Spain

Copyright (c) 2014 by authors and Scientific Research Publishing Inc.

This work is licensed under the Creative Commons Attribution International License (CC BY).

http://creativecommons.org/licenses/by/4.0/

c) (i)

Open Access

\begin{abstract}
Research on the relation between family and happiness has focused on the micro level and considered the effects of an individual's place in the family system, such as whether or not one is married and exchange of support with kin. Macro level differences in the family system as such have received little attention as yet. In this paper we consider regional differences in family types in Europe and explore the relationship with average happiness. Data on dominant family type in regions are taken from Todd (1990), who distinguishes five family types: 1) absolute nuclear; 2) egalitarian nuclear; 3) communitarian; 4) stem family; and 5) incomplete stem family. Data on average happiness in regions are taken from the Eurobarometer surveys. Average happiness appears to be highest in regions where family pattern of "absolute nuclear" prevails and lowest in the regions where "egalitarian nuclear" family dominates. Control for economic prosperity in regions does not change this picture. A possible interpretation of these findings is that freedom adds more to happiness than equality does. It is not true for types of freedom. If horizontal freedom (intragenerational freedom) seems to be important in terms of well-being, the results are much less convincing as far as vertical freedom (intergenerational freedom) is concerned. The findings might have some far reach contribution in the field of family policy.
\end{abstract}

\section{Keywords}

Family Type, Happiness, Life Satisfaction, Stem Family, Nuclear Family, Communitarian Family

\section{Introduction}

Interest in happiness has been on the rise in the last decades, not only among the general public but also among

How to cite this paper: Brulé, G., \& Veenhoven, R. (2014). Average Happiness and Dominant Family Type in Regions in Western Europe around 2000. Advances in Applied Sociology, 4, 271-288.

http://dx.doi.org/10.4236/aasoci.2014.412031 
policy makers and scientists. The scientific interest manifest in a growing number of publications in the field, some 500 books and articles appeared in 2010 and the yearly growth rate is about 5\% (Veenhoven, 2011: Section, 3).

\subsection{World Database of Happiness}

To date there are some 7000 scientific publications on the topic in Bibliography of Happiness (Veenhoven, 2013a). The findings of this strand of research are gathered in the World Database of Happiness, the world's most comprehensive database on the topic ${ }^{1}$. Each separate finding is described on a "finding page" using a standard format and terminology.

Much of this research is about personal characteristics of happy or unhappy people, such as personality, goals and values. Another strand of research is about the external conditions that make people happy or unhappy. This article is about the latter type of research.

\subsection{Happiness in Nations}

Part of the research on external conditions for happiness is about happiness in nations. This research has revealed great differences across nations; for instance, on scale 0 to 10 , Zimbabwe had an average of 3.0 whereas Denmark had an average of 8.3. All findings of this kind are gathered in the collection "Happiness in Nations" of the World Database of Happiness (Veenhoven, 2012b).

Reasons for differences in average happiness across nations have been sought in various factors, such as climate (Barrington-Leigh, 2008), values (e.g. Schwartz (1999), Inglehart et al. (2000), Smith et al. (2002), Senik (2011), Brulé \& Veenhoven (2012 b,c)), economic development (e.g. Schyns (1998), Frey \& Stutzer (2002), Layard (2005), Bjornskov et al. (2007), Stanca (2010)), in institutional quality (e.g. Ott (2010)), and in history (e.g. Brulé \& Veenhoven (2012a)). Together these nation characteristics explain about 75\% of the observed differences in average happiness across nations (Veenhoven, 2010). These findings are gathered in the report "Findings on Happiness and Conditions in One's Nation" of the World Database of Happiness (Veenhoven, 2012c). To date this report involves 630 findings.

\subsection{Happiness in Regions}

Happiness in regions within nations has received less attention. Oswald and Wu (2009) explored happiness in US states and concluded, after controlling for individual characteristics, that some states had significantly higher level of life satisfaction than others. Research has been done to study life satisfaction across provinces and regions such as Morrison (2007) in New Zealand, Clark (2003) in Great-Britain, Rampichini and Schifini D’Andrea (1998) in Italy or Brereton, Clinch and Ferreira (2008) in Ireland. Okulicz-Kozaryn (2010) studied the link between income and life satisfaction in regions throughout Europe. The differences in happiness across regions, tend to be smaller than differences across nations. The findings from this strand of research are gathered in the report "Findings on Happiness and Region in Nation" of the world Database of happiness (Veenhoven, 2012d). To data this report involves 71 research findings.

\subsection{Position in Society}

Next to research on the effect of societal characteristics on average happiness, there is much research on the effects of position within a society on the happiness of individuals. Much of that research is about socioeconomic position in society, typically measured with income, occupational prestige and employment. Likewise there is much research on the effect on happiness of one's position in socio-emotional networks, as measured with things like marital status, family size and contacts with kin. Embedding in socio-emotional networks appears to matter more for happiness than socio-economic status.

\subsection{Much Research on Happiness and Family Life}

Most of the research on happiness and embedding in socio-emotional networks is about family life. The bulk of research is about the relationship between current family life and happiness of adults, such as the difference in

1http://www1.eur.nl/fsw/happiness/ 
happiness between married and single individuals (Raschke (1977), Hamplova (2006)) or the link between happiness and task division between spouses (Lu \& Lin, 1998). There is also quite some research on the effects of family characteristics on the happiness of children and in that strand also on long-term consequences, such as the effects of broken home in childhood on happiness in adulthood. Findings of this strand of research are also gathered in the World Database of Happiness, in particular in the reports "Happiness and Family" (Veenhoven, 2012e) and "Happiness and Marriage" (Veenhoven, 2012f), which currently contains respectively 504 and 880 research findings.

\subsection{Little View on Effect of Family Type}

In spite of much research on one's position in the local family system, there is little research on the effect of happiness of family systems as such. Still, there are good reasons to expect that family type shapes happiness. As a matter of fact, happiness of individuals depends to some extent on their "social capital" and some family types may generate more of that than others. Happiness depends also heavily on individuals' psychological autonomy, which may not be equally fostered in all family types. In particular, we might think that some families promotes social capital whereas some others tend to enhance psychological autonomy; both are conducive to happiness so it seems interesting to us to understand if there is one that is most important to happiness or if they are both equally important.

According to Duranton et al. (2009), the taxonomy of family systems has several advantages. First, it captures two fundamental dimensions, which matter within the family and outside the family. For instance, Gross and McIlveen (1998) point out that early childhood experiences are influenced by adults values and behavior, and that there is a clear percolation between family values and society values. Second, this two-dimension classification is an ideal level of complexity that enable relatively easy analysis without falling in the oversimplification of "weak versus strong" family ties. Finally, the family structures are relatively homogeneous in regions and the cohabitation of different systems is quite weak so the family types are empirically measured and quite homogeneous within regions. However, this is tempered by a few examples of coexisting family systems that will be further discussed, as they raise some interesting questions. Therefore, we aim at tackling one of the main weaknesses in the current literature in which the link between family structures and happiness barely goes beyond a "weak versus strong ties" debate.

\subsection{Implication for Family Policy}

These considerations have some important implications when considering family policies; indeed, some policies may foster kids' autonomy while some others might foster family bonds. A large part of this is cultural but one might wonder what to do in certain circumstances: foster autonomy or family bonds? The answer is far from being obvious; this paper aims at bringing some material and at contributing in answering this question to some extent. As we will see, using Todd's work, we use the laws for the wills in order to see if a certain region is dominated by egalitarian ties or not. Finding a difference between the regions that are dominated by equal traditions and the ones that are not can encourage policy-makers to rethink the laws about the wills. Likewise, we determine the links between parents and children by the cohabitation or not of different generations and depending if the sons leave the parental house once married. A difference between the regions with and without dominant cohabiting families might as well provide policy-makers to think of the cohabitants of generations. The family type seems to be an adequate angle to look at the impact of several family characteristics.

\subsection{Macro-Level Analysis}

Data regarding dominant family types are available at the sub-regional level (NUTS 3), the data on happiness at the regional level (NUTS 2); this means we need to perform a macro-level analysis at two different levels, the national and the regional ones. Not only is macro-level analysis the only way for us to investigate the link between family structures and happiness, it also enables us to put a foot in the field of the culture of happiness since, as Merton (1949) pointed out, the family is the main cultural transmitter. Comparing the maps of happiness and family structures is a way to dig into the culture of happiness through the lens of family structures.

\subsection{Plan of This Paper}

Below we will start by explaining what we mean by "happiness" and how happiness is measured and to what 
extent average happiness differs across European nations and regions. Next, we will consider family types, following Todd (1990) who distinguished 5 types and measured the prevalence of these in Europe. On that basis we explore the statistical relation between happiness and dominant family types in nations and in regions. We find the highest happiness in nations and regions where the "absolute nuclear" family type prevails and the lowest where the "egalitarian nuclear" family dominates. Having established these basic facts, we go on to explore possible explanations, and consider the effects of freedom and equality.

\section{Happiness}

What is "happiness" precisely? How can we measure happiness in nations? Does happiness differ across nations? Does happiness differ within nations across regions?

\subsection{Concept}

The word "happiness" is used in many different ways. This paper is about happiness in the sense of life satisfaction. Following Veenhoven (1984) we define happiness as the degree to which someone evaluates the overall quality of his or her present life-as-a-whole positively. In other words, how much one likes the life one lives.

\subsection{Measurement}

Happiness is something we have in mind and things we have in mind can be assessed using questioning. Questions on happiness can be framed in many ways, directly or indirectly, using single or multiple items. An overview of acceptable questions is available in the collection "Measures of Happiness" of the World Database of Happiness (Veenhoven, 2012d).

\subsection{Data on Average Happiness}

In this study we use happiness as measured in the bi-annual Eurobarometer surveys; these surveys are carried out by the European Commission to monitor public opinion. These data are aggregated at the regional level; by regional level in this study, we mean NUTS units (Nomenclature of Territorial Units for Statistics).

The question is the following: "On the whole how satisfied are you with the life you lead? 4: very satisfied; 3: fairly satisfied; 2: not very satisfied; 1 : not at all satisfied”. This question has been used at least once every year since the start of the Eurobarometer in 1973. In this study we use the Eurobarometer 44.2 Bis (1996) surveys, which involve respondents aged 15 years and over, resident in each of the Member States (about 3000 respondents in Belgium, Denmark, Ireland, The Netherlands, Austria, Portugal, Finland, and Sweden; about 6000 respondents in West Germany, Spain, France, Italy and Great Britain). From this dataset we computed average scores per nation and within nations also by region; for the regions we used the "administrative regional units". They thus represent the whole territory of the Member States according to the EUROSTAT-NUTS II (see http://www.ec.europa.eu/eurostat/ramon/nuts/home_regions_en.html). The regional value is taken as the average of different regions, which all consist of thousands of respondents; just a few regions have a very limited number of respondents and should be taken with great care: Corse (Fr, 66 respondents), La Rioja (Sp, 347 respondents), Basilicata (It, 483 respondents), Baden Würtenberg (DE, 309 respondents), Cumbira (UK, 483 respondents), East Midlands (UK, 157 respondents), Uppsala Ostra Mellansverige (SE, 159 respondents), Etelä Savo (FI, 125 respondents).

\section{Family Type}

Comparative research on family systems, initiated by Le Play (1871) has shown considerable differences in family systems around the world, such as the difference between stem families and the nuclear family and between matrifocal families and patrifocal patterns. Various consequences of prevalence of one family type or another have been considered, such as effects on economic growth (Sagart, Todd, \& Little, 1992). Todd (1990) defines families according to two main characteristics: the relationship between parents and children and the equality between children. For the first characteristics, the relationship between parents and children can be defined as authoritarian on one side or libertarian on the other side. In order to measure this characteristic, Todd used family registers and inspected these throughout Europe. 
Several generations co-living under the same roof is a sign of the prominence of the parents' authority on the children and was therefore categorized as "authoritarian". In such families, the elder son does not leave the family house once after his wedding; he stays under the authority of the father. Likewise, unmarried daughters stay under the authority of the father in the first place and then under the authority of the brothers. On the other hand, when families are nuclear (merely composed of their nucleus), i.e. when the parents alone or with their children, the links between the generations are considered loose and the family system "libertarian". In such families, when individuals grow up or once they get married (or even before), they leave the parental house and found their own family.

Beside this authoritarian/libertarian distinction depicting the link among generations, Todd also defines equality within generations: equality define family structures where this value or practice is present, unequal when this value or practice is not present or unconsidered. In order to classify families in one category or the other, Todd looks into the documents of the wills: when the will clearly defines the willingness of distributing equally the goods among the siblings (or at least the brothers), the family system is considered as "equal"; if not or if the wills can be distributed unequally among children, then the family system is considered as "unequal".

\subsection{Todd's Family Types}

The combination of two possibilities on each axis (freedom and equality) gives four main types of family structures...

1) Families that combine equality and liberalism are called egalitarian nuclear by Todd.

2) The other nuclear families are called absolute nuclear as liberty seems to be the only value considered.

3) In the "egalitarian nuclear" system, there is a prominence of stronger relations between the children, at least until the inheritance is completely divided after the parents' death. When "authority" is combined with "inequality", the family is considered as authoritarian stem family. In such a family, the property is typically passed to the eldest son and the values of inequality are institutionalized.

4) Conversely, when "authority" is combined with "equality", the family is considered as communitarian. In such families, the sons stay living in the parental house, under the authority of the father but the goods and the property are expected to be distributed equally among the siblings (or at least the brothers) after the death of the parents.

5) To these four types of family structures, Todd adds another one, the incomplete stem family; he observed that in certain areas where authoritarian and egalitarian laws prevailed (which would entail a "communitarian" type of family), in the facts, the distribution was largely inegalitarian (a "stem family" type of heritage). Contrary to communitarian types, the married brothers do not cohabit together, and contrary to stem family types, there are laws that pledge for an egalitarian distribution. In these areas, the strength of the primogeniture tradition tends to override any such egalitarian lawmaking. Therefore, this fifth "hybrid" type completes the picture.

In his latest work, Todd has defined 16 family types (Todd, 2011), all derived from the five basic levels, but the level of complexity as well as the lack of corresponding maps makes it impractical to use, but we will occasionally refer to it. Table 1 below summarizes the different types of family.

\subsection{Data of Prevalence of the Family Types in Regions}

In order to obtain the data for the "liberty" characteristics, Todd first used censuses from Western European countries in the 1950s and 1960s. As the conditions in Europe at that period were particular in this after-war period, for instance due to potentially more pronounced cohabitation, he cross-checked the data obtained with nearly 200 historical monographs in order to verify the validity of the data obtained and checked whether these monographs contradicted his classification. Apart from a few adjustments, Todd claims that the family structures are surprisingly stable throughout time, and that there were very little difference with monographs that were 500

Table 1. Family types in Todd's classification.

\begin{tabular}{ccc}
\hline & Egalitarian & Unegalitarian \\
\hline Authoritarian & Communitarian & Stem (complete or incomplete) \\
Libertarian & Nuclear egalitarian & Absolute nuclear \\
\hline
\end{tabular}


years old and more. For instance, the prevalence of stem families in French Brittany (Finistère), Galicia, Wales and Scotland coincides with areas where Celtic populations took refuge two millennia ago. The area corresponding with the current communitarian central Italy ties in closely with the area of Etruscan civilization in preRoman times.

As for the measurement of the "equality" characteristics, Todd also used relatively recent data for the whole of Western Europe while verifying whether or not the patterns he discovered find some echo in historical monographs. In order to objectivize this equality factor, he analyzed the mechanism of repartition of family property among siblings after the death of the parents. Equality is considered at its maximum when family property is divided evenly among siblings or (more usually) among brothers. This factor can be observed looking into inheritance laws and practices. In some regions, the laws oblige an equal repartition of heritage while in some other regions, there is a remarkable indifference to the principle of equality; in this case, the parents are either free to divide the way they feel is the most appropriate, or the parents are forced to choose an unique child that will inherit everything.

Todd has performed the analysis throughout more than 200 regions. Most regions are labeled with one family type, some other with two. Figure 1 shows the map of Europe according to the different types.

\section{Method}

Our research question is whether these family types are equally conducive to happiness in contemporary society. To answer that question we compare average happiness in geographical areas to see if happiness is higher in areas where a particular family pattern dominates. This is a macro-level analysis.

\subsection{Units}

As "areas" we consider both nations and regions. Since we use data on family type gathered by Todd, we limit to 13 European countries. In order to obtain the matrix presenting the happiness level and the family type of all regions of the 13 countries, we combine the data of Todd and of the Eurobarometer; the finest level of detail in the Eurobarometer is the regional level (NUTS 2) whereas Todd use the infraregional level (NUTS 3). Therefore we need to aggregate the data of Todd to match the level of the Eurobarometer (NUTS 2).

Some regions are largely homogeneous in terms of family type so the family type of the whole region is trivial; however, in a few rare cases, regions are composed of more than one family type. In this case, we had to find out which family type was dominant in the given region. To so do, we counted the geographical sub-units (NUTS 3) for each family type and took the dominant family type for the whole region (NUTS 2).

\subsection{Analysis}

We first compared nations and inspected whether average happiness is higher or lower in nations where a particular family type dominates. Such differences may be due to other nation characteristics than family type and therefore we compared next across regions within nations. Finally, we checked whether these latter differences can be attributed to other regional characteristics.

\section{Results}

We found that average happiness is highest in regions where family pattern of "absolute nuclear" prevails and lowest in the regions where "egalitarian nuclear" family dominates. This pattern appears both in the comparison of nations and in the comparison of regions with in nations.

\subsection{Comparison at the Aggregated Level}

Data on average happiness and dominant family type in the 13 European nations are presented in Table 2. The values were obtained taking the average values of happiness in regions across Europe, without any national aggregation. One clear difference strikes the eye, the dramatic difference in average happiness between countries where the "absolute nuclear" family type dominates (such as Denmark) and the countries where the "nuclear egalitarian" family is quite common (such as Spain). These differences in family type account for up to $40 \%$ of the range in average happiness, which is the difference between happiness in regions dominated by egalitarian 


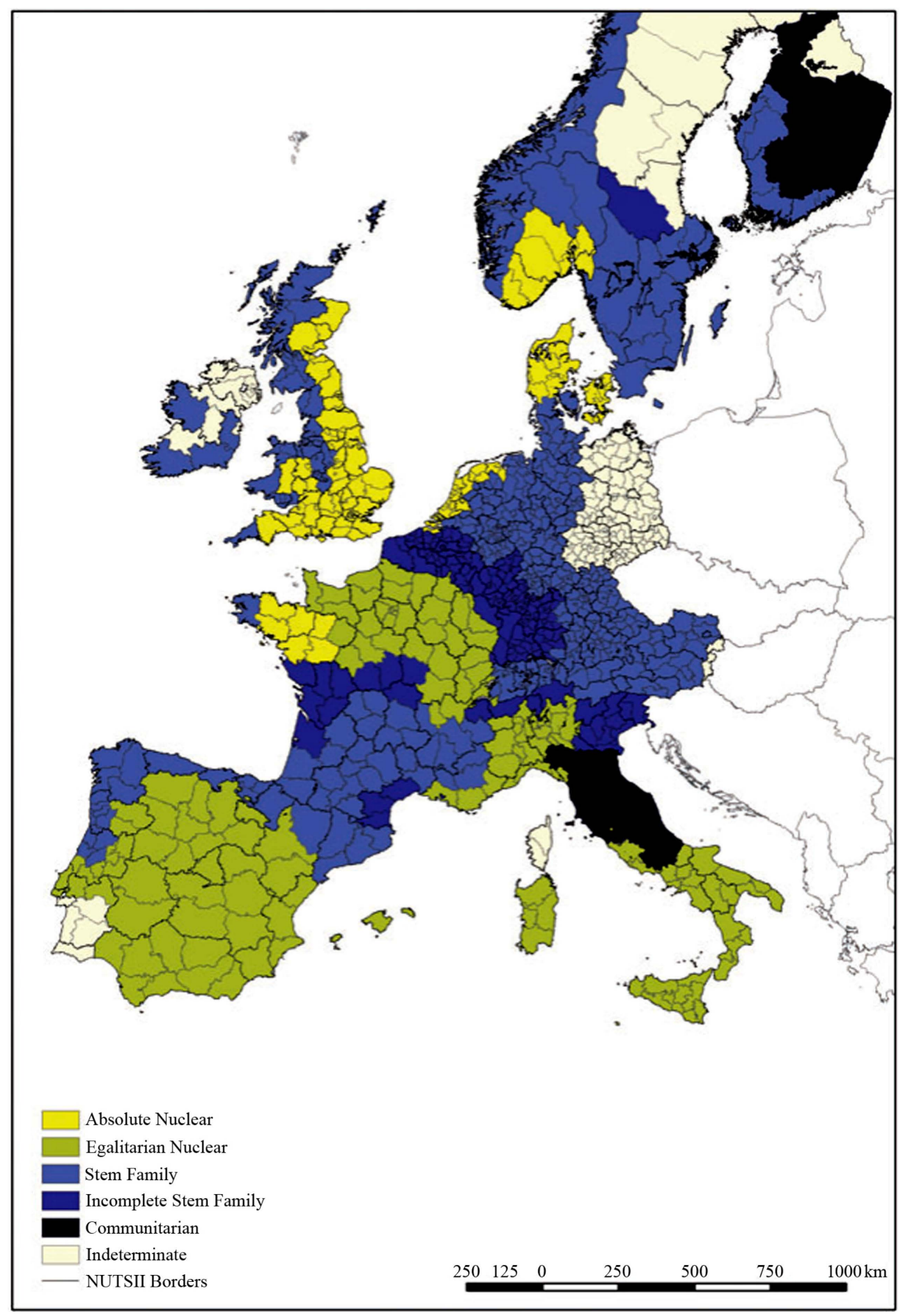

Figure 1. Family types in Europe.

nuclear families (2.84) and those dominated by absolute nuclear families (3.24) on a total range of almost 1 point throughout Europe between the least happy and the happiest region (2.65 - 3.62). There is no real difference between the two (or three) authoritarian models, even if happiness in stem family (complete or incomplete) is slightly higher than in communitarian family. Looking at the aggregated levels of happiness at the European level, regions where the "absolute nuclear" dominates seem to be the most fertile ground for happiness of the citizens, whereas regions where "egalitarian nuclear" dominate seem to be the least. 
Table 2. Average happiness per family type in Europe (see complete results in Appendix Tables A1-A6).

\begin{tabular}{cccc}
\hline & Happiness & Countries & Number of regions \\
\hline Communitarian & 3.06 & Fi, It & 18 \\
Stem complete & 3.07 & Be, De, Ie, Fi, Fr, Pt, Se, Sp & 85 \\
Stem incomplete & 3.00 & Be, Fr, It, Nl, Uk, & 31 \\
Nuclear egalitarian & 2.84 & Fr, It, Sp, Pt & 29 \\
Absolute nuclear & 3.24 & Dk, Fr, Nl, Uk & 41 \\
\hline
\end{tabular}

However, these differences in average happiness across European nations can be due to other things than family type. The difference fit an earlier observed North-South difference in happiness, which has been attributed to variation in values (e.g. Inglehart, 1977), hierarchy (Brulé \& Veenhoven, 2012a) and governance quality (Ott, 2010). Possibly the correlation with family type is just a byproduct of such differences and has little effect on happiness by itself. Let's have a closer look at this to see if thess first impressions resist a finer analysis.

\subsection{Comparison across Regions within Nations}

Let us now look at the effects of the family types within nations. The regional level has several advantages, because, as we will see, it is often a better scale to observe variation in dominant family types. Second, it enables also to largely cancel out the national level effects. Policies are mostly enforced at a national level and regions are typically subjected to the same rules. Out of the 13 countries, 7 are either homogeneous in terms of family types (Belgium, Germany) or lacking of complete or comparable data (Finland, Ireland, Norway, Sweden, Switzerland) to be analyzed and cannot help us in the infranational comparisons. We will therefore base our analysis on 6 nations: France, Italy, the Netherlands, Portugal, Spain, the United Kingdom. They will help us in different ways and to different extent.

The ranking of happiness throughout nations per family types is presented in Figure 2. Details of happiness and family types for all countries are presented in Appendix. Happiness ranges from 2.65 (egalitarian nuclear in Portugal) to 3.62 (absolute nuclear in Denmark).

\subsubsection{France}

France is an interesting nation to compare family types, as it is the only country that has all five family types, even if the communitarian type is mixed with the dominant nuclear egalitarian one. The pattern of difference in France fits largely with the above pattern of differences across nations. The happiest regions are Alsace, the Germanic-influenced region with its stem family model and the Celtic-influenced Brittany and Pays de la Loire, in which the absolute nuclear family type dominates. When gathering per family type, almost the same order withstands with the absolute nuclear model, present in the West of France first again, then the stem family model (complete and incomplete) and then the nuclear egalitarian.

What is striking in the French case and not visible at the European level is the fact that the regions that have a coexistence of two family models, that is egalitarian nuclear with communitarian influences (Limousin (2.71) and Auvergne (2.64)) are by far the unhappiest and are among the least happy regions of Western Europe. According to Todd (2011: p 409), this area is the only "bi-local communitarian" type in Europe and can also be seen as a hybrid type stuck between the egalitarian nuclear type of the Paris basin and the stem family from the Aquitine basin. Maybe this particular hybridism of system is not favorable for happiness. An explanation could be that the coexistence of two family systems might lead to anomie, introduced by Durkheim (1897) in the context of coexisting religions for instance; co-existing families might lead to a similar effect. However, this observation could also be tempered as this coexistence can also be observed in the south eastern region of ProvenceAlpes-Côte d'Azur; no major difference can be observed between the level of happiness of the region (2.81) and the average level of nuclear egalitarian families (2.80).

The difference between average happiness in egalitarian nuclear and absolute nuclear families (0.12) accounts for $40 \%$ of the total range of life satisfaction in France, i.e. the difference between Auvergne (2.64) and Alsace (2.96). The differences between stem family and egalitarian nuclear families (10\%) and between incomplete 


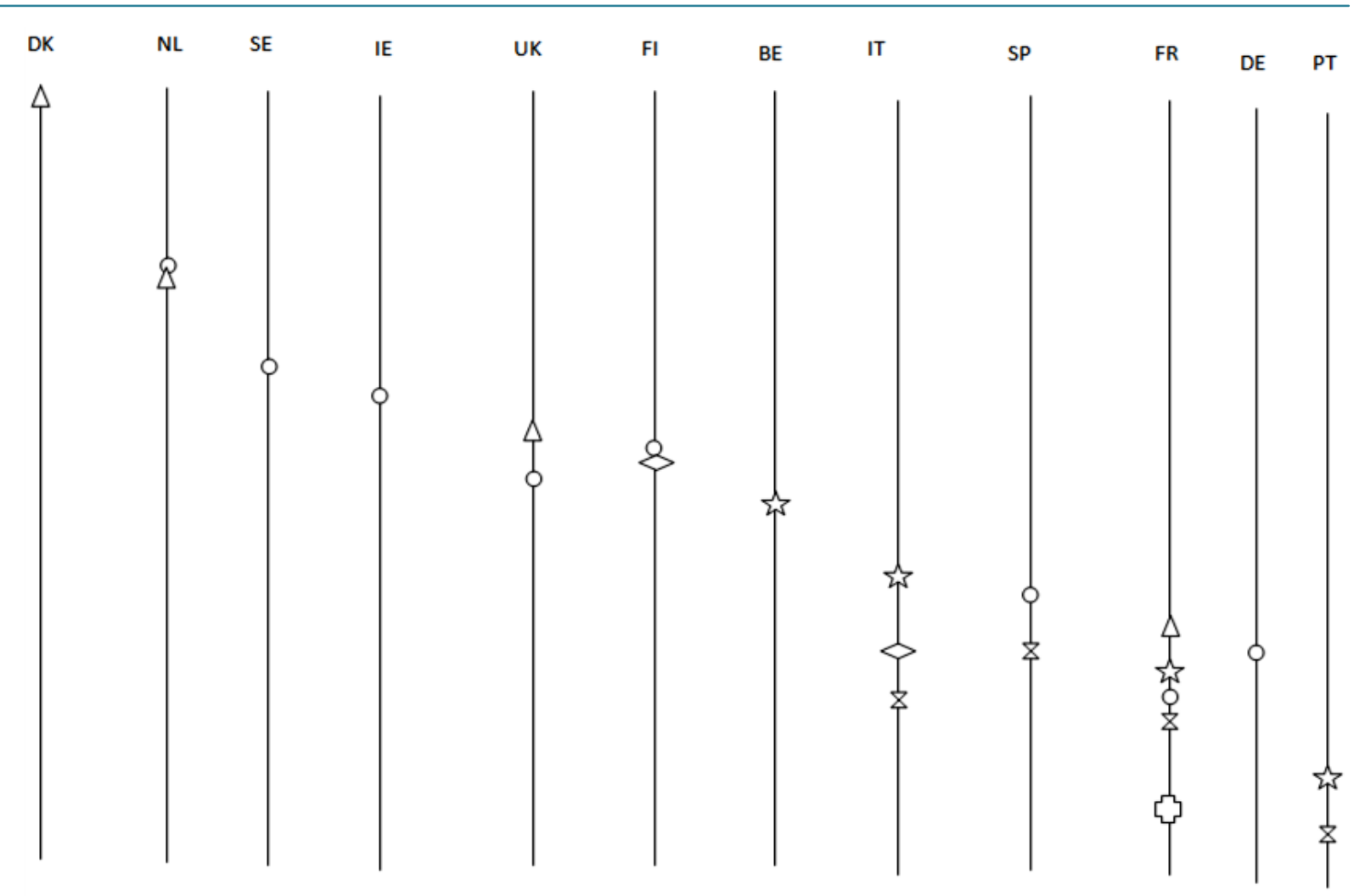

Dominant family type:

$\triangle$ Absolute Nuclear

O Stem Family

$\checkmark$ Communitarian

is Incomplete Stem Family

\& Egalitarian Nuclear

Egalitarian Nuclear+Communitarian

Figure 2. Average happiness ranking per family type in 13 European nations around 2000.

stem family and egalitarian nuclear families (20\%) are in between. The happiness pattern per family type in France is very close to the European one, and the aggregated trend is largely verified in the French case.

\subsubsection{Italy}

Italy is the second country with the most diversity in family types with just the absolute nuclear family type missing. Happiness in the Italian family types reveals the same logic in terms of happiness with stem family ranking first, then communitarian and then nuclear egalitarian. The happiest part is the North-East, and particularly the agricultural region of Trentino (3.13), then come the communitarian central Italy, which according to Todd, coincides with the Etruscan occupation in pre-Roman times, and then the egalitarian nuclear, present in the North-West and in the South of Italy. This confirms the difference at the nation level and regions with dominant communitarian families are happier than regions with dominant nuclear egalitarian ones. The difference between (incomplete) stem families and egalitarian nuclear families (0.16) accounts for a substantial $42 \%$ of the total Italian difference, between Sardegna (2.75) and Trentino (3.13).

\subsubsection{The Netherlands}

The Netherlands do not show large differences in family models; the North, protestant is largely formed with absolute nuclear families while the south and east, more agricultural, is populated with stem families. There are no differences in happiness; in general, the Netherlands are very homogeneous in terms of happiness with a difference of only 0.12 between the unhappiest region (Groningen) and the happiest (Gelderland). It is therefore difficult to draw any conclusions from this country, except that in the Dutch case, regions dominated by incomplete stem families are slightly happier than regions dominated by absolute nuclear families. The difference is 
small, but this makes our family hierarchy imperfect. Maybe this hides other factors that we do not foresee now, but this might require some further investigation.

\subsubsection{Portugal}

In Portugal, the North of the country is populated with stem families, while the south the nuclear egalitarian pattern dominates. The former show a slightly higher level of happiness compared with the latter, with the North and the Center being happier than the south and the Lisboan region. However, these results should be interpreted with care as this concerns only two regions in the North and two in the South, the other ones being not identified in terms of family models. However, this is consistent with the European hierarchy.

\subsubsection{Spain}

Spain shows the same pattern as Portugal with stem families in the North showing a slightly higher level of happiness than nuclear egalitarian families in the South. The difference between the two sets of countries represents 35\% of the total Spanish range given by the difference between Aragon (3.01) and Andalucía (2.75).

\subsubsection{United Kingdom}

United Kingdom is divided in two parts, a western part dominated by stem families and an eastern part dominated by absolute nuclear families. The British trend confirms the wider one with a higher level of absolute nuclear families in comparison with stem families.

\subsection{Control for Possible Spuriousness}

Is the difference in happiness really in family or is it in regional characteristics that happen to go with family such as agrarian business or income per head?

\subsubsection{Economic Prosperity?}

Let's have a look at the regional wealth, as measured with disposable regional income. The family structures might just be a consequence of a certain level of development or wealth, and if so the difference in happiness could be a matter of wealth rather than family organization. For instance, the cohabitation of several generations might just be a consequence of an impossibility for the young generations to afford accommodation. However, if we look at the different countries, it appears not to be the case. France is relatively homogeneous in terms of income per head, but it is clear that happiness is not a consequence of difference in income as regions dominated by egalitarian nuclear families are the richest and the unhappiest, while absolute nuclear and incomplete stem families are the least wealthy and the happiest. Portugal follows the same pattern with the south being richer and unhappier, while the North is poorer and happier. Spain and Italy follow a different pattern as the unhappy regions, dominated by egalitarian nuclear families are also the poorest. All in, it means the conclusions are unlikely affected by income per head for Southern Europe.

In the Netherlands the income per head is the same in regions dominated by absolute nuclear families and by regions dominated by incomplete stem families. In the United Kingdom, regions dominated by absolute nuclear families are globally richer than regions dominated by incomplete stem families, even if, because of the aggregation level, we could not have the disposable income per head for all regions, so we made an average with the regions with available information.

A quantitative analysis confirms this view with adjusted means being the same as the unadjusted means in the different countries. See in the respective country tables.

This confirms the fact that family types and prosperity or modernity seem to be uncorrelated. As Todd states in another co-written article, "the various family cycles do not correspond very well to particular levels of cultural or economic development. Nuclear and stem cycles, in particular, appear among both very developed and very primitive groups.” (Sagart, Todd, \& Little, 1992).

\subsubsection{Agrarian Economy?}

We could imagine that another factor could be the agrarian share in each region that could affect the family type and Todd (1990) confirms this intuition: there is a link between agrarian system and family type. The farmer ownership is a fertile ground for stem family to flourish with the property inherited by the oldest son for instance. 
Large farms and egalitarian nuclear families mix well as the large farm is divided into independent sub-systems, even if it is far from being systematic as in England, absolute nuclear families flourish in large farms; however, absolute nuclear families are more present in tenant farming with a relative independence of the farmer to the owner and of the children to the parents. Communitarian families accommodate very well in sharecropping cultures with the refusal of a monetary system and the possible constitution of large communities.

These differences of agriculture types can explain the differences in family type. Could the difference in happiness be a secondary effect of the agrarian share? Looking at Todd (1990), we can see that once again, the situation differs a lot depending on the countries. In France, the agrarian regions of the West and South-West are among the happiest, whereas the North and North-East, that has virtually no agriculture has the unhappiest regions. In Spain, the regions that have the least agrarian share are either among the happiest in the North of Spain or among the unhappiest with the South-West of Spain. Italy has its happiest regions in the North, which is the least agrarian part. The situations are thus very different from a country to another, but all in all, there seems to be no agriculture effect on the happiness of the inhabitants of the regions, at least not in the agrarian share of the people. Actually, the influence of agriculture on happiness might be more in the type of farming more than in the importance of the agrarian community. Ownership and relationships between owners and farmers might be more decisive than the share of the community in the regions. Therefore, agriculture would be more a factor of explanation than a bias in the analysis between happiness and family types.

\subsection{Main Observable Facts}

1) Average happiness is higher in regions where the "absolute nuclear" family type dominates than in the “egalitarian nuclear” model.

2) Average happiness in regions where the "stem family" model dominates is systematically higher than regions where "nuclear egalitarian” dominates.

3) Average happiness is higher in regions dominated by a "stem family" model than in regions that are communitarian or with a communitarian inflexion.

4) Regions where "nuclear absolute" and regions where stem family dominate have a comparable level of happiness.

\subsection{Conclusions}

By combining these observations, we can draw the following conclusions:

1) Regions dominated by inegalitarian families have a level of well-being that is systematically higher than in regions with egalitarian families; horizontal freedom, the relative independence of kids towards each other, seems to be of primary importance.

2) As far as relationships between the generations are concerned, the link is way less obvious; libertarian relationships seems to be more favorable than authoritarian, but the difference is far from being systematic; the link between vertical freedom, the relative independence of children towards vis-à-vis parents, and happiness is almost non-existent.

If we have to summarize in one sentence, we could say that at the regional level, intergenerational freedom seems to have very little influence on people's happiness whereas intragenerational level seems to have a strong influence.

\section{Discussion}

So this exploration does reveal a consistent difference. Below we will consider a possible explanation and note some limitations.

\subsection{Explanations}

Why live people happier in areas where absolute nuclear family type dominates than in areas where the egalitarian nuclear family type prevails? Regions where stem families (authoritarian only) have levels of well-being that are systematically higher than in communitarian (authoritarian and egalitarian), which is the system that offers the least variance. In that context we will first review the evidence that freedom fosters happiness. Next we will consider why the absolute nuclear family pattern is most conducive to freedom and why the egalitarian type 
is not, and following the same logic why it is more present in the stem family than in the communitarian family.

\subsubsection{Why Has Vertical Freedom No Impact on Well-Being?}

It is a fairly intriguing fact; in the line of previous studies where the strong link between vertical freedom and happiness, for instance in companies, has been highlighted, we could have expected similar results among families, but as a matter of fact, the link is far from being obvious, and when it is present, it is fairly limited. How to explain this? Maybe the advantages and drawbacks between libertarian and authoritarian family balance each other. Maybe the gain in freedom is counterbalanced by a feeling of insecurity due to the weak bonds between generations; conversely, the feeling of security among authoritarian families may compensate a relative lack of freedom.

\subsubsection{Why Is Horizontal Freedom So Important?}

Among all the different facts, this is the clearer and most redundant pattern. At the aggregated level and at the regional level, regions dominated by the inegalitarian or non-egalitarian families are systematically happier than regions dominated by egalitarian families. Why is that? We see at the family level a pattern we have observed in our previous work, freedom, in all its form, whether it is actual (social, psychological, potential) or perceived, is one of the most important determinants of happiness. But then what type of freedom? Horizontal freedom seems to be a fertile ground for happiness to develop whereas this observation seems much less true for vertical freedom. How to explain this?

Forced equality reduces the freedom of parents and in a way reduces the chances of optimal allocation. It might be indeed more sensible to give the property and the goods to the child that is the most likely to make a good use of it instead of distributing them equally among kids that are unequally responsible. In many ways, forced equality reduces freedom, and this seems to be confirmed by this comparison between egalitarian and absolute nuclear families. This seems to be confirmed by the fact that "authority only", present in stem families, seems to be higher than authority combined with equality (communitarian), as the examples of France and Italy show.

Is equality a brake to happiness? Whereas equality might be morally desirable, it does not seem to pay off in terms of happiness, as it might not allow the best way to reach an "optimal allocation". Another explanation is that in a system that values more equality, you depend less on yourself and more on the system; in other words, your locus of control is less internal than in the case of "freedom only", where everything depends on you and your locus of control is purely internal. Focusing on income distribution in America, Oishi, Kesebir and Diener (2011) have shown that there was some link between income inequality and happiness among low income respondents, but not among high income respondents. They also showed that for low income respondents the link between income inequality and income was mediated by perceived unfairness. This article shows also that the correlation between equality and happiness is not as clear and positive as one could expect. Whereas this might sound selfish, this seems to be the best way to reach happiness. This might even question the ethics of happiness "is happiness ethical"? This has been largely discussed by Veenhoven (2010). Maybe the angle brought by this article will add another light on this ongoing debate.

\subsection{Limitations}

This first exploration of the link between family type and happiness is probably not the last word. Future research should deal with the following limitations.

\subsubsection{Level of Analysis}

When dealing with comparing levels of life satisfaction and another variable such as family types, an ideal approach would naturally go towards a multilevel analysis in order to confront a macro-level analysis with microlevel data, that is to say data at the individual level. Whereas this data exists for life satisfaction thanks to Eurobarometer, this data is not available for family types. The macro-analysis, comparing aggregated level with the regional level is therefore the best we can do.

\subsubsection{Classification of Family Types}

Despite the conclusions drawn from this study, a few restrictions can be observed; first, when talking about li- 
berty and especially equality, it is not always easy to distinguish laws, practices and values. As Todd himself recognized by creating a hybrid type in 1990 (incomplete stem family with practices not meeting laws) and by creating 16 family types in his later work, it is not always easy to classify every region with a single table. As for any taxonomy, we need to be aware that "liberty" or "equality" are not binary, i.e. "free" or not "free", "equal" or "not equal", but rather a continuum and that two regions with the same family type might present some variations in equality and freedom. This is a general limitation of any taxonomic work: too much complexity makes the comparison unpractical or even unfeasible whereas too much simplicity makes the conclusions less robust. We tried to work with an adequate level of complexity; this could naturally be discussed.

\subsubsection{Confouding Factors}

In this study we checked two possible confounders, economic prosperity and agrarian share and none of them can explain the difference of happiness across regions. An anthropological approach could show that the type of culture has more to do than the agrarian share itself. In a previous work, we studied the link between the type of fishing/agrarian society and the current happiness of people; a future interesting work could be to look more into the link between the type of culture and the happiness of people.

\subsubsection{Causality}

Empirical research can show a statistical relationship, but often we can only guess about the causal factors behind.

In this case we made an educated guess in terms of freedom. Though plausible, this will not be the only possible explanation.

\section{Conclusion}

Average happiness is highest in European areas where the "absolute nuclear" family type dominates, that is, families characterized by a relatively low level of family commitment and low emphasis on equality. More generally, regions dominated by families with a relative horizontal freedom have higher levels of well-being. Conversely, there seems to be no difference between regions dominated by families with and without vertical freedom. Those differences appear consistently at the regional and aggregated level. Intragenerational equality does not seem to be a fertile ground for happiness.

\section{References}

Barrington-Leigh, C. P. (2008). Weather as a Transient Influence on Survey-Reported Satisfaction with Life. Source MPRA Paper No. 25736, 2008, Munich.

Bjornskov, C., Dreher, A., \& Fisher J. A. (2007). On Gender Inequality and Life-Satisfaction: Does Discrimination Matter? Discussion Paper 2007-07 University of Gallen, Department of Economics, Switzerland.

Brereton F., Clinch, J. P., \& Ferreira, S. (2008). Happiness, Geography and the Environment. Ecological Economics, 65, 386-396. http://dx.doi.org/10.1016/j.ecolecon.2007.07.008

Brulé, G., \& Veenhoven, R. (2012a). Why Are Latin Europeans Less Happy? The Impact of Social Hierarchy. In M. Canevacci (Ed.), Polyphonic Anthropology: Theoretical and Empirical Cross-Cultural Fieldwork, Rijeka: Intech. http://dx.doi.org/10.5772/38061

Brulé, G., \& Veenhoven, R. (2012b). Happiness and Freedom in Bations: Why Are the Finns Happier than the French? Submitted.

Brulé, G., \& Veenhoven, R. (2012c). Democratic Teaching and Happiness in Developed Nations. Submitted.

Clark, A. E. (2003). Inequality-Aversion and Income Mobility: A Direct Test. DELTA Working Paper, 2003-11.

Duranton, G., Rodríguez-Pose, A., \& Sandall, R. (2009). Family Types and the Persistence of Regional Disparities in Europe. Economic geography, 85, 23-47. http://dx.doi.org/10.1111/j.1944-8287.2008.01002.x

Durkheim, E. (1897). Le suicide. Étude de sociologie. Paris: Felix alcan.

Frey, B., \& Stutzer, A. (2002). Happiness and Economics. Princeton, NJ: Princeton University Press.

Gross, R., \& McIlveen, R. (1998). Psychology: A New Introduction. London: Hodder and Stoughton.

Hamplova, D. (2006). Satisfaction with Life, Happiness, and Family Status in Twenty-One European Countries. Sociologicky Casopis-Czech Sociological Review, 42, 35-55. 
Inglehart, R. (1977). Values, Objective Needs, and Subjective Satisfaction among Western Publics. Comparative Political Studies, 9, 429-458.

Inglehart, R., \& Klingemann, H. D. (2000). Genes, Culture, Democracy, and Happiness. Culture and Subjective Well-Being, 165-183.

Layard, R. (2005). Happiness: Lessons from a New Science. London: Penguin Books.

Le Play, F. (1871). L'organisation de la famille (The Organisation of the Family). Whitefish, MT: Kessinger Publishing.

Morrison, P. (2007). Subjective Well-Being and the City. Social Policy Journal of New Zealand, 31, 74-103.

Merton, R. K. (1949). Social Culture and Social Structure. New York City: Macillan.

Okulicz-Kozaryn, A. (2010). Geography of European Life Satisfaction. Social Indicators Research, 101, 435-445.

Oishi, S., Kesebir, S., \& DIener, E. (2011). Income Inequality and Happiness. Psychological Science, 22, 1095-1100. http://dx.doi.org/10.1177/0956797611417262

Oswald, A., \& Wu, S. (2009). Well-Being across America: Evidence from a Random Sample of One Million U.S. Citizens. University of Warwick Working Paper. http://www2.warwick.ac.uk/fac/soc/economics/staff/academic/oswald/oswaldwuwellbeing2009.pdf

Ott, J. C. (2010). Good Governance and Happiness in Nations: Technical Quality Precedes Democracy and Quality Beats Size. Journal of Happiness Studies, 11, 353-368. http://dx.doi.org/10.1007/s10902-009-9144-7

Rampichini, C., \& Schifini D’Andrea, S. (1998). A Hierarchical Ordinal Probit Model for the Analysis of Life Satisfaction in Italy. Social Indicators Research, 44, 41-69. http://dx.doi.org/10.1023/A:1006888613727

Raschke, H. (1977). Family Structure, Family Happiness and Their Effect on College Students' Personal and Social Adjustement. Family Court Review, 15, 30-33.

Sagart, L., Todd, E., \& Little, B. (1992). Hypothesis on the Origins of the Communal Family System. Diogenes, 40, 145-182. http://dx.doi.org/10.1177/039219219204016009

Schyns, P. (1998). Crossnational Differences in Happiness: Economic and Cultural Factors Explored. Social Indicators Research, 43, 3-26. http://dx.doi.org/10.1023/A:1006814424293

Schwartz, S. H. (1999). Cultural Value Differences: Some Implications for Work. Applied Psychology: An International Review, 48, 23-48. http://dx.doi.org/10.1111/j.1464-0597.1999.tb00047.x

Senik, C. (2011). The French Unhappiness Puzzle: The Cultural Dimension of Happiness. Working Paper No 2011-34.

Smith, P., Peterson, M., \& Schwartz, S. (2002). Cultural Values, Sources of Guidance, and Their Relevance to Managerial Behavior: A 47-Nation Study. Journal of Cross-Cultural Psychology, 33, 188-208. http://dx.doi.org/10.1177/0022022102033002005

Stanca, L. (2010). The Geography of Economics and Happiness: Spatial Patterns in the Effects of Economic Conditions on Well-Being. Social Indicators Research, 99, 115-133. http://dx.doi.org/10.1007/s11205-009-9571-1

Todd, E. (1990). L'invention de l'Europe (The Invention of Europe). Paris: Seuil.

Todd, E. (2011). L'origine des systèmes familiaux-Tome 1: L'Eurasie (The Origin of Family Systems-Tome 1: Eurasia). Paris: Seuil.

Veenhoven, R. (1984). Conditions of Happiness. Dordrecht: Springer. http://dx.doi.org/10.1007/978-94-009-6432-7

Veenhoven, R. (2010). Greater Happiness for a Greater Number: Is that Possible and Desirable? Journal of Happiness Studies, 11, 605-629. http://dx.doi.org/10.1007/s10902-010-9204-z

Veenhoven, R. (2011). World Database of Happiness: Example of a Focussed Findings Archive. Working Paper No. 169, German Data Forum RatSWD.

Veenhoven, R. (2012a). Bibliography of Happiness. World Database of Happiness, Erasmus University Rotterdam. http://worlddatabaseofhappiness.eur.nl/hap_bib/bib_fp.php

Veenhoven, R. (2012b). Happiness in Nations. World Database of Happiness, Erasmus University Rotterdam. http://worlddatababaseofhappiness.eur.nl/hap_nat/nat_fp.php

Veenhoven, R. (2012c). Findings on Happiness and Conditions on One's Nation. World Database of Happiness, Erasmus university Rotterdam. http://worlddatabaseofhappiness.eur.nl/hap_cor/top_sub.php?code=N4

Veenhoven, R. (2012d). Findings on Happiness and Region in Nation. World Database of Happiness, Erasmus University Rotterdam. http://worlddatabaseofhappiness.eur.nl/hap_cor/top_sub.php?code=N9

Veenhoven, R. (2012e). Measures of Happiness. World Database of Happiness, Erasmus University Rotterdam. http://worldedatabaseofhappiness.eur.nl/hap_quesr/hqi_fp.htm 


\section{Appendix}

Table A1. Happiness and family types in France.

\begin{tabular}{|c|c|c|c|c|c|c|}
\hline & $\begin{array}{c}\text { Life } \\
\text { satisfaction }\end{array}$ & $\begin{array}{l}\text { Family } \\
\text { type }\end{array}$ & $\begin{array}{l}\text { Average happiness } \\
\text { per family type }\end{array}$ & $\begin{array}{c}\text { Regional } \\
\text { disposable income }\end{array}$ & $\begin{array}{l}\text { Average regional income } \\
\text { per family type }\end{array}$ & $\begin{array}{c}\text { Adjusted means } \\
\text { for happiness }\end{array}$ \\
\hline Pays de la Loire & 2.89 & AN & & 10,230 & & \\
\hline Bretagne & 2.94 & AN & 2.92 & 10,229 & 10,229 & 2.92 \\
\hline Limousin & 2.71 & $\mathrm{EN}+\mathrm{C}$ & & 10,535 & & \\
\hline Auvergne & 2.64 & $\mathrm{EN}+\mathrm{C}$ & 2.67 & 10,556 & 10,450 & 2.67 \\
\hline Provence-Alpes-Côte d'Azur & 2.81 & EN & & 10,758 & & \\
\hline Lorraine & 2.77 & EN & & 10,238 & & \\
\hline Île de France (Paris) & 2.83 & EN & & 13,159 & & \\
\hline Haute-Normandie & 2.77 & EN & & 10,610 & & \\
\hline Corse & 2.88 & EN & & 9,012 & & \\
\hline Champagne-Ardenne & 2.76 & EN & & 10,353 & & \\
\hline Centre & 2.78 & EN & & 10,815 & & \\
\hline Bourgogne & 2.82 & EN & & 10,890 & & \\
\hline Basse-Normandie & 2.79 & EN & & 10,270 & & \\
\hline Franche-Comté & 2.80 & EN & 2.80 & 10,439 & 10,654 & 2.80 \\
\hline Poitou-Charentes & 2.80 & ISF & & 10,205 & & \\
\hline Nord Pas de Calais & 2.81 & ISF & & 8,942 & & \\
\hline Alsace & 2.96 & ISF & 2.86 & 11,010 & 10,052 & 2.86 \\
\hline Rhône-Alpes & 2.81 & SF & & 10,970 & & \\
\hline Picardie & 2.76 & SF & & 10,381 & & \\
\hline Midi-Pyrénées & 2.87 & SF & & 10,204 & & \\
\hline Languedoc-Roussillon & 2.85 & SF & & 9,716 & & \\
\hline Aquitaine & 2.84 & SF & 2.83 & 10,559 & 10,336 & 2.83 \\
\hline
\end{tabular}

Table A2. Happiness and family types in Italy.

\begin{tabular}{|c|c|c|c|c|c|c|}
\hline Regions & $\begin{array}{l}\text { Life } \\
\text { satisfaction }\end{array}$ & $\begin{array}{l}\text { Family } \\
\text { types }\end{array}$ & $\begin{array}{l}\text { Happiness per } \\
\text { family type }\end{array}$ & $\begin{array}{c}\text { Regional } \\
\text { disposable income }\end{array}$ & $\begin{array}{c}\text { Average regional } \\
\text { income per family type }\end{array}$ & $\begin{array}{l}\text { Adjusted means } \\
\text { for happiness }\end{array}$ \\
\hline Emilia Romagna & 2.93 & $\mathrm{C}$ & & 15,925 & & \\
\hline Lazio & 2.81 & $\mathrm{C}$ & & 12,908 & & \\
\hline Marche & 2.92 & $\mathrm{C}$ & & 12,642 & & \\
\hline Molisee Abruzzi & 2.88 & $\mathrm{C}$ & & 10,309 & & \\
\hline Toscana & 2.89 & C & & 13,566 & & \\
\hline Umbria & 2.88 & $\mathrm{C}$ & 2.89 & 12,500 & 12,975 & 2.90 \\
\hline Basilicata & 2.79 & EN & & 8,844 & & \\
\hline Calabria & 2.77 & EN & & 8,146 & & \\
\hline
\end{tabular}


Continued

\begin{tabular}{|c|c|c|c|c|c|c|}
\hline Campania & 2.77 & EN & & 8,161 & & \\
\hline Liguria & 2.90 & EN & & 13,953 & & \\
\hline Lombardia & 2.98 & EN & & 15,401 & & \\
\hline Milano & 2.95 & EN & & & & \\
\hline Puglie & 2.77 & EN & & 8,642 & & \\
\hline Sardegna & 2.75 & EN & & 9,100 & & \\
\hline Sicilia & 2.75 & EN & 2.83 & 8,430 & 10,084 & 2.82 \\
\hline Friuli. VeneziaGiulia & 2.93 & ISF & & 13,784 & & \\
\hline Trentino & 3.13 & ISF & & & & \\
\hline Valle d'Aostae Piemonte & 2.95 & ISF & & 14,969 & & \\
\hline Veneto & 2.95 & ISF & 2.99 & 13,518 & 14,090 & 2.99 \\
\hline
\end{tabular}

Table A3. Happiness and family types in the Netherlands.

\begin{tabular}{|c|c|c|c|c|c|c|}
\hline Regions & $\begin{array}{l}\text { Life } \\
\text { satisfaction }\end{array}$ & $\begin{array}{l}\text { Family } \\
\text { types }\end{array}$ & $\begin{array}{l}\text { Happiness per } \\
\text { family type }\end{array}$ & $\begin{array}{l}\text { Regional disposable } \\
\text { income }\end{array}$ & $\begin{array}{c}\text { Average regional } \\
\text { income per family type }\end{array}$ & $\begin{array}{l}\text { Adjusted means for } \\
\text { happiness }\end{array}$ \\
\hline Friesland & 3.41 & NA & & 12,500 & & \\
\hline Groningen & 3.33 & NA & & 12,700 & & \\
\hline Noord-Holland & 3.39 & NA & & 15,200 & & \\
\hline Utrecht & 3.39 & NA & & 15,200 & & \\
\hline Zeeland & 3.35 & NA & & 13,000 & & \\
\hline Zuid-Holland & 3.37 & NA & 3.37 & 14,500 & 13,850 & 3.37 \\
\hline Drente & 3.41 & SF & & 14,000 & & \\
\hline Gelderland & 3.45 & SF & & 14,000 & & \\
\hline Limburg & 3.36 & SF & & & & \\
\hline Noord-Brabant & 3.39 & SF & & 14,400 & & \\
\hline Overijssel & 3.44 & SF & 3.41 & 13,000 & 13,850 & 3.42 \\
\hline
\end{tabular}

Table A4. Happiness and family types in Portugal.

\begin{tabular}{|c|c|c|c|c|c|c|}
\hline Regions & $\begin{array}{l}\text { Life } \\
\text { satisfaction }\end{array}$ & $\begin{array}{l}\text { Family } \\
\text { types }\end{array}$ & $\begin{array}{l}\text { Happiness per } \\
\text { family type }\end{array}$ & $\begin{array}{c}\text { Regional } \\
\text { disposable income }\end{array}$ & $\begin{array}{c}\text { Average regional income } \\
\text { per family type }\end{array}$ & $\begin{array}{c}\text { Adjusted means } \\
\text { for happiness }\end{array}$ \\
\hline Alentejo & 2.69 & EN & & 7128 & & \\
\hline Lisboa et Vale do Tejo & 2.62 & EN & 2.65 & 9001 & 8064 & 2.68 \\
\hline Centro & 2.70 & ISF & & 6902 & & \\
\hline Norte & 2.75 & ISF & 2.72 & 6579 & 6740 & 2.69 \\
\hline Acores & 2.79 & unknown & & & & \\
\hline Algarve & 2.67 & unknown & & & & \\
\hline Madeira & 2.84 & unknown & & & & \\
\hline Madeira & 2.71 & unknown & & & & \\
\hline
\end{tabular}


Table A5. Happiness and family types in Spain.

\begin{tabular}{|c|c|c|c|c|c|c|}
\hline Regions & Happiness & Family type & $\begin{array}{l}\text { Happiness per } \\
\text { family type }\end{array}$ & $\begin{array}{c}\text { Regional } \\
\text { disposable income }\end{array}$ & $\begin{array}{l}\text { Average regional income } \\
\text { per family type }\end{array}$ & $\begin{array}{l}\text { Adjusted means } \\
\text { for happiness }\end{array}$ \\
\hline Andalucia & 2.84 & EN & & 6989 & & \\
\hline Baleares & 2,92 & EN & & 10,258 & & \\
\hline Castilla Leon & 2.96 & EN & & 8638 & & \\
\hline Castilla-Mancha & 2.92 & EN & & 7543 & & \\
\hline Extremadura & 2.94 & EN & & 6344 & & \\
\hline La Rioja & 2.91 & EN & & 9816 & & \\
\hline Madrid & 2.87 & EN & & 10,217 & & \\
\hline Murcia & 2.85 & EN & & 7174 & & \\
\hline Valenciano & 2.90 & EN & 2.90 & 8356 & 8370 & 2.90 \\
\hline Aragon & 3.01 & SF & & 9598 & & \\
\hline Asturias & 2.93 & SF & & 8182 & & \\
\hline Cantabria & 2.94 & SF & & 8657 & & \\
\hline Cataluna & 2.89 & SF & & 10,184 & & \\
\hline Galicia & 2.97 & SF & & 7636 & & \\
\hline Navarra & 3.00 & SF & & 10,715 & & \\
\hline Pais Vasco & 2.98 & SF & 2.96 & 10,482 & 9350 & 2.96 \\
\hline Canarias & 2.90 & unknown & & 8007 & & \\
\hline
\end{tabular}

Table A6. Happiness and family types in the United Kingdom.

\begin{tabular}{|c|c|c|c|c|c|}
\hline Regions & $\begin{array}{c}\text { Life } \\
\text { satisfaction }\end{array}$ & $\begin{array}{l}\text { Family } \\
\text { types }\end{array}$ & $\begin{array}{l}\text { Happiness per } \\
\text { family type }\end{array}$ & $\begin{array}{c}\text { Regional } \\
\text { disposable income }\end{array}$ & $\begin{array}{c}\text { Average regional income } \\
\text { per family type }\end{array}$ \\
\hline Avon Gloucestershire Wiltshire & 3.24 & NA & & & \\
\hline Bedfordshire Hertfordshire & 3.21 & NA & & & \\
\hline Berksshire Buckinghamshire Oxfordshire & 3.20 & NA & & & \\
\hline Borders Central Fife Lothian Tayside & 3.16 & NA & & & \\
\hline Cleveland Durham & 3.19 & NA & & & \\
\hline Dorset Somerset & 3.20 & NA & & & \\
\hline East Anglia & 3.21 & NA & & & \\
\hline Essex & 3.23 & NA & & & \\
\hline Grampian & 3.24 & NA & & & \\
\hline Greater London & 3.08 & NA & & 14,110 & \\
\hline Hampshire Isle of wight & 3.18 & NA & & 12,115 & \\
\hline Hereford and Worcester Warwickshire & 3.17 & NA & & 12,146 & \\
\hline Humberside & 3.12 & NA & & & \\
\hline Isle of Wright & 3.22 & NA & & & \\
\hline
\end{tabular}




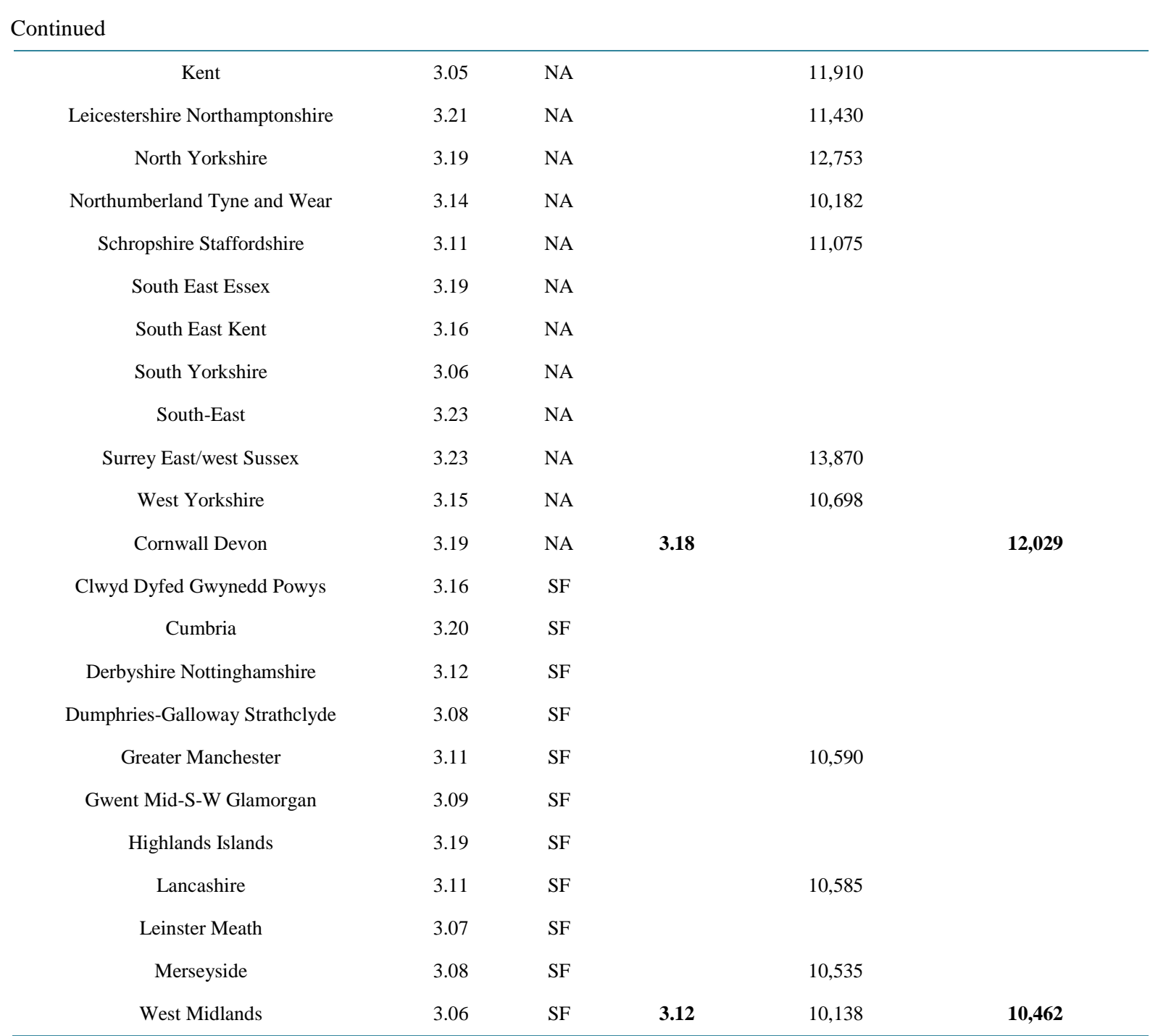


Scientific Research Publishing (SCIRP) is one of the largest Open Access journal publishers. It is currently publishing more than 200 open access, online, peer-reviewed journals covering a wide range of academic disciplines. SCIRP serves the worldwide academic communities and contributes to the progress and application of science with its publication.

Other selected journals from SCIRP are listed as below. Submit your manuscript to us via either submit@scirp.org or Online Submission Portal.
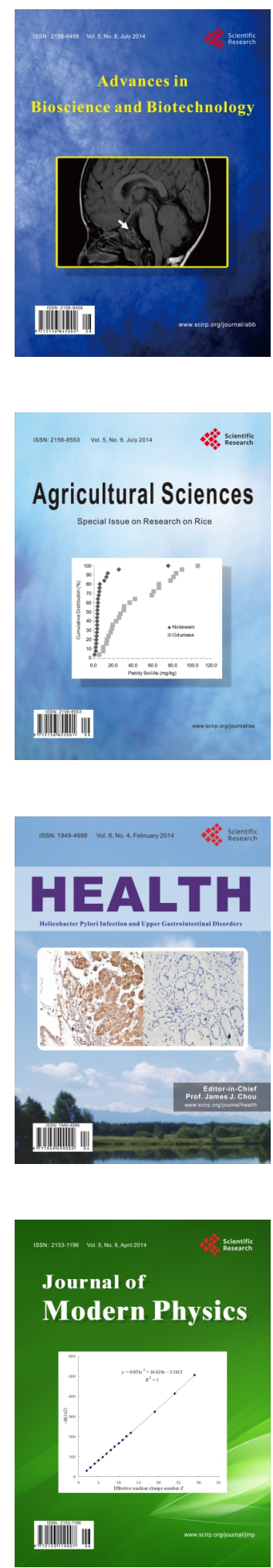
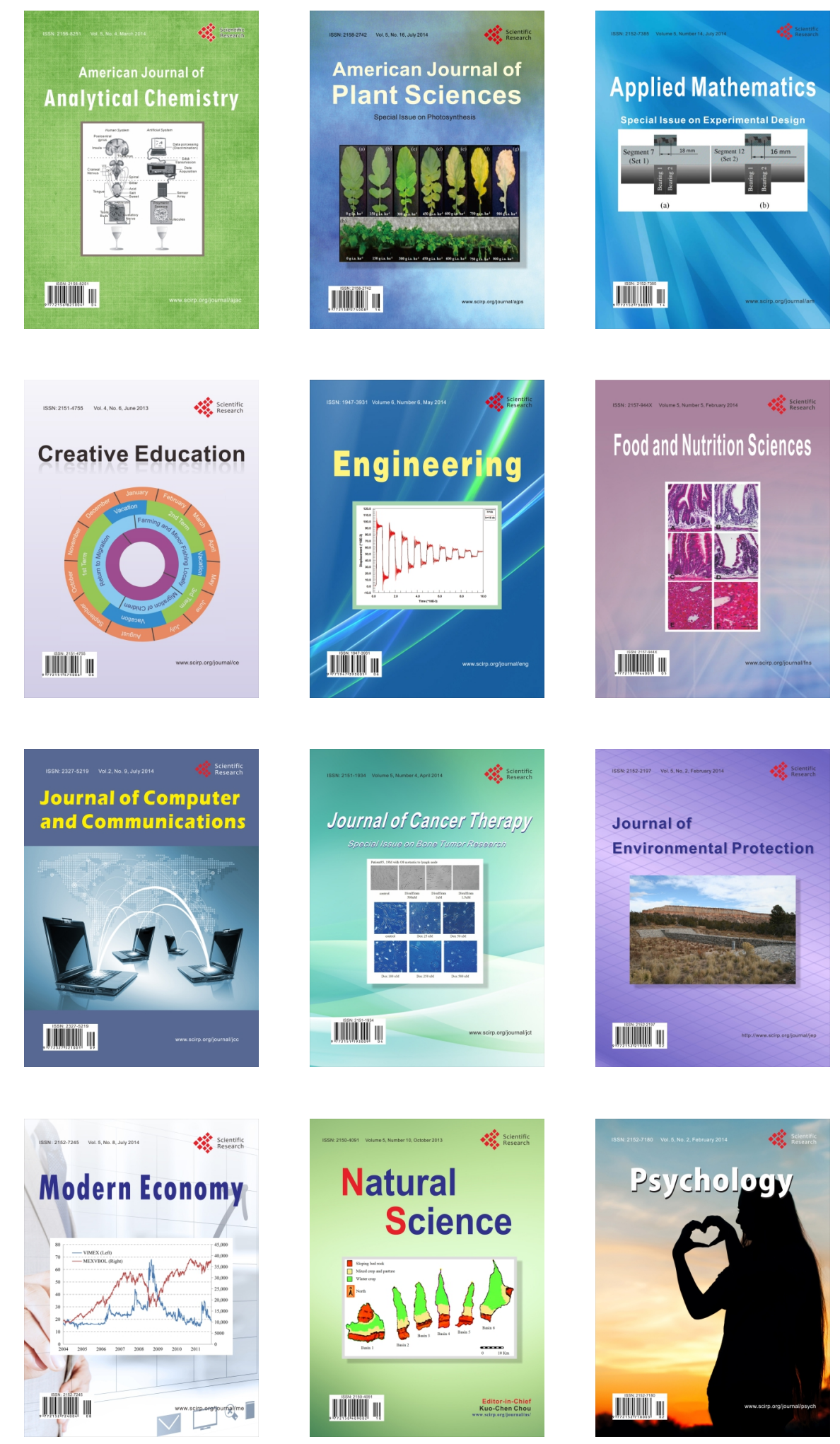